\title{
Transatlantica
}

Revue d'études américaines. American Studies Journal

\section{Lauric Guillaud. La Terreur et le sacré : la nuit gothique américaine.}

Paris : Michel Houdiard Editeur, 2003, 280 p.

\section{Max Duperray}

\section{(2) OpenEdition}

\section{Journals}

Édition électronique

URL : http://journals.openedition.org/transatlantica/871

DOI : $10.4000 /$ transatlantica.871

ISSN : 1765-2766

Éditeur

AFEA

Référence électronique

Max Duperray, "Lauric Guillaud. La Terreur et le sacré : la nuit gothique américaine. », Transatlantica [En ligne], 1 | 2005, mis en ligne le 24 avril 2006, consulté le 29 avril 2021. URL : http://

journals.openedition.org/transatlantica/871 ; DOI : https://doi.org/10.4000/transatlantica.871

Ce document a été généré automatiquement le 29 avril 2021.

\section{c) (i) $९$}

Transatlantica - Revue d'études américaines est mis à disposition selon les termes de la licence Creative Commons Attribution - Pas d'Utilisation Commerciale - Pas de Modification 4.0 International. 


\title{
Lauric Guillaud. La Terreur et le sacré : la nuit gothique américaine.
}

Paris : Michel Houdiard Editeur, 2003, 280 p.

\author{
Max Duperray
}

1 Michel Houdiard est un éditeur qui se spécialise dans la publication d'ouvrages originaux, du domaine anglophone entre autres et américain en particulier. Le livre récent de Lauric Guillaud, spécialiste des paralittératures et du romanesque d'aventure, ne fait pas exception. Joliment sous-titré « la nuit gothique américaine »-en souvenir de la nuit américaine de Truffaut ? - son livre témoigne d'un envers du décor, en posant l'espace américain de l'imaginaire sombre; cet imaginaire est à la fois un pressentiment des colons important leurs mythologies anxiogènes et un donné immanent au «territoire-terreur », vécu comme «topos maléfique». La démonologie puritaine anime la figure de la sorcière, signe de la transgression des limites et intronise le concept stimulant de "frontières barbares", frontières textuelles aussi entre les expériences rapportées - récits d'enlèvement par exemple - et leurs rendus horrifiques et/ ou fascinants. Ainsi Lauric Guillaud pose-t-il le cadre de son étude en se portant aux sources de la "romance américaine » à connotation gothique, devenant «le moteur paradoxal » de la création littéraire américaine, sous le signe de Brockden Brown, S. Rowson, W.G.S.Simms, voire Fenimore Cooper (celui de The Spy (1821) surtout).

2 Trois ou quatre chapitres essentiels viendront structurer le développement. À l'intérieur de cet «espace ambivalent ", l'auteur place d'abord de nombreux récits de découverte souvent motivés par le tropisme de vestiges anciens, introuvables mais imaginables; Crèvecœur devenu fermier du nouveau monde et malmené par les peurs archaïques, Freneau, auteur de The House of Night, une véritable épitaphe du rêve américain( rédigée vers la fin des années1770)...et d'autres. On apprendra en passant que Dickens n'avait pas aimé l'Amérique, déprimé qu'il avait été par la morbidité des paysages et la décrépitude urbaine. Bien entendu l'expédition de Lewis et Clark - à laquelle un chapitre entier est consacré ; inspirée par l'idéologie jeffersonienne, elle se 
mue en une utopie tragique pouvant nourrir l'imagination d'E.A.Poe - surtout dans le texte de son Journal of Julius Rodman (1840).

Un autre volet est ensuite celui, visuel, de la représentation picturale. A l'âge du pittoresque, les artistes, peintres ou poètes, célèbrent le "Wild» sublime (le poète Alexander Wilson est très proche de Burke) en aidant le paysage à supplanter la mode du portrait, avec à leur tête Thomas Cole, contaminé par la fièvre de la colonisation des grands espaces. Ses cycles picturaux vont osciller entre la glorification de l'histoire (The Voyage of Life, 1839) et la tentation allégorique et cyclique. Là encore Guillaud esquisse une possible filiation avec le « Maelström » de Poe.

Dans ce contexte, Jack London méritait reconnaissance et il est heureux qu'il revienne à la mémoire d'une époque qui l'a parfois un peu oublié ou relégué à la littérature enfantine. Les récits du grand Nord sont judicieusement répertoriés sous le signe d'une " échappée régressive " au cours de laquelle le protagoniste, répondant à l'appel du chaos - « The call of the wild»- doit déchiffrer les messages abscons de la nature, entre « signification et futilité ». Après tout Jack London trouve, à l'instar de Stevenson peutêtre, la même énigme dans la nature silencieuse que dans les bas-fonds de Londres (The People of the Abyss, 1903).

Enfin on arrive là où on devait aller, aux échantillons d'une fiction fantastique - une littérature que Lauric Guillaud connaît bien - : Charlotte Perkins Gilman, entre autres, pour une nouvelle moins célèbre que l'inévitable "Yellow Paper", "The Giant Wisteria », « conte gothique de la frontière ».

6 Comme un avocat montant son dossier, l'auteur verse les pièces de son témoignage pour faire revivre la sensibilité historique des fondateurs de la littérature d'outreAtlantique. Il s'exclame en fin de course : «j'ai voulu épouser le regard de ces êtres de jadis, exilés, perdus mais toujours fascinés... ». De cette fascination, il reste ici quelque chose, même si elle n'empêche pas l'élaboration du travail universitaire savant appuyé sur sa bibliographie, ses notes et glossaire, tout ce qui le rendra utilisable comme outil de travail.

\section{INDEX}

Thèmes : Recensions

\section{AUTEUR}

\section{MAX DUPERRAY}

Université de Provence 